\title{
Elementos de inclusividade no ensino de Ciências aos estudantes com deficiência intelectual: uma revisão bibliográfica
}

\author{
Elements of inclusiveness in Science teaching to students with intellectual disabilities: a literature \\ review
}

Elementos de inclusión en la enseñanza de las Ciencias a estudiantes con discapacidad intelectual: una revisión de la literatura

\section{Resumo}

A fim de suprir as necessidades de uma prática pedagógica inclusiva no Ensino de Ciências, neste estudo objetiva-se identificar elementos de inclusividade como a flexibilização curricular no ensino de ciências, para estudantes com deficiência intelectual. Para tanto, utiliza-se como metodologia de pesquisa a revisão bibliográfica das produções científicas brasileiras em artigos, trabalho de conclusão de curso, teses e dissertações publicadas nos últimos cinco anos. A análise dos dados obtidos evidenciou a necessidade da formação continuada do docente para a inserção desses elementos no seu planejamento, contemplando o uso de tecnologias assistivas, atividades lúdicas, o enfoque CTSA que favorece o desenvolvimento do pensamento crítico bem como embasamento para discutir as relações entre conhecimento e currículo no contexto inclusivo.

Palavras-chave: Currículo inclusivo; Formação docente; Ensino regular.

\begin{abstract}
In order to meet the needs of an inclusive pedagogical practice in Science Education, this study aims to identify elements of inclusiveness such as curriculum flexibility in science education for students with intellectual disabilities. For this purpose, the bibliographical review of Brazilian scientific productions in articles, course completion work, theses and dissertations published in the last five years is used as research methodology. The analysis of the data obtained evidenced the need for the continuing education of the teacher for the insertion of these elements in his planning, contemplating the use of assistive technologies, playful activities, the CTSA approach that favors the development of critical thinking as well as a basis to discuss the relationships between knowledge and curriculum in an inclusive context.
\end{abstract}

Keywords: Inclusive curriculum; Teacher education; Regular education.

\begin{abstract}
Resumen
Con el fin de satisfacer las necesidades de una práctica pedagógica inclusiva en la Enseñanza de las Ciencias, este estudio tiene como objetivo identificar elementos de inclusión como la flexibilidad curricular en la enseñanza de las ciencias para estudiantes con discapacidad intelectual. Por tanto, se utiliza como metodología de investigación la revisión bibliográfica de las producciones científicas brasileñas en artículos, trabajos de finalización de curso, tesis y disertaciones publicadas en los últimos cinco años. El análisis de los datos obtenidos evidenció la necesidad de la formación continua de los docentes para incluir estos elementos en su planificación, incluyendo el uso de tecnologías asistenciales, actividades recreativas, el enfoque CTSA que favorece el desarrollo del pensamiento crítico, así como una base para discutir la relaciones entre conocimiento y currículo en el contexto inclusivo.
\end{abstract}

Palabras clave: Currículo inclusivo; Formación de profesores; Educación regular. 


\section{Introdução}

A pesquisa é talvez a arte de se criar dificuldades fecundas e de criá-las para os outros. Nos lugares onde havia coisas simples, faz-se aparecer problemas.

(Pierre Bourdieu, 1992)

Para realizar este estudo, definimos como objetivo: identificar elementos de exclusividade como a flexibilização curricular no ensino de Ciências para estudantes com alguma deficiência, especificamente deficiência intelectual, nas publicações científicas brasileiras dos últimos cinco anos. Para tanto, neste capítulo/artigo, apresentamos uma revisão bibliográfica que realizamos a partir dos descritores relacionados ao nosso tema central.

Conforme Oliveira (1998), o conceito que Vygotsky elabora quando aborda o desenvolvimento nas condições orgânicas adversas é o de compensação que explica a aprendizagem e o desenvolvimento de pessoas com e sem deficiências. Sendo assim, é possível vislumbrar outra educação escolar: que se empenhe em criar ou ampliar zonas de desenvolvimento proximal e que se paute antes no que está íntegro do que no que se apresenta deficitário garantindo o direito à aprendizagem. Esse direito abrange a educação inclusiva, em apreço a não discriminação que, por sua vez, é previsto em nossa Constituição (1988) além dos pactos e tratados internacionais dos quais o Brasil é signatário. Nessa perspectiva:

[...] esse direito significa, primariamente, o direito de igual acesso à educação, que deve ser concedido a todos, especialmente para os níveis mais basilares do ensino. Assim, o conteúdo inicial (mínimo) do direito à educação é o de acesso ao conhecimento básico e capacitações, que devem ser oferecidas de forma regular e organizada (Tavares, 2013, p.732).

Dentro da escola regular a educação inclusiva é um processo amparado por diversas legislações. Entre elas destacam: Constituição Federal do Brasil (1988), Declaração de Salamanca (1994), Declaração Mundial de Educação para Todos (1990), Política Nacional de Educação Especial na Perspectiva da Educação Inclusiva (2008), Estatuto da Criança e do Adolescente (ECA/1990), a Lei de Diretrizes e Bases da Educação (LDB-9394/96) que estabelece a oferta da educação especial preferencialmente na rede regular de ensino, o que exige adequação da escola e qualificação dos professores.

Em conformidade com a Política Nacional de Educação Especial na Perspectiva da Educação Inclusiva (Brasil, 2008), os estudantes com deficiências são compreendidos como aqueles com deficiência intelectual, auditiva, visual, física e deficiência múltipla, transtornos globais do desenvolvimento e altas habilidades/superdotação. No caso da deficiência intelectual $^{1}$, por mais que não seja possível reverter esse quadro em função de envolver o desenvolvimento neurológico, conforme Santos (2017), é possível a aprendizagem de conhecimentos igualmente aos demais estudantes sem deficiência. Dessa forma, se o estudante com deficiência intelectual for estimulado por meio de ações pedagógicas que usam recursos apropriados e com objetivos definidos, ele pode apresentar um bom desempenho acadêmico em diversos casos (Miranda \& Pinheiro, 2016; Silva, Shimazaki \& Menegassi, 2017).

Nesta pesquisa, partimos da concepção de que uma das áreas do conhecimento nas quais os estudantes com deficiência intelectual podem apresentar avanços em relação à sua aprendizagem é em Ciências (Miranda e Pinheiro, 2016). Para isso, conforme os autores, é fundamental a utilização de diferentes estratégias didáticas nas quais o professor tenha uma atenção às especificidades dos estudantes com deficiência intelectual. Nesta pesquisa percebemos que ainda é pequeno o

${ }^{1} \mathrm{O}$ conceito de deficiência intelectual utilizado nesta pesquisa é aquele empregado pela American Association on Intellectual and Developmental Disabilities (AAIDD), que define a deficiência intelectual como uma deficiência caracterizada por consideráveis limitações no que se refere ao funcionamento intelectual e ao comportamento adaptativo e que abrange muitas habilidades sociais e práticas cotidianas, sendo expressa antes dos 18 anos de idade (AAIDD, 2018). A AAIDD compreende o funcionamento intelectual como capacidades mentais gerais que se relacionam à aprendizagem, ao raciocínio, à resolução de problemas, entre outros. Enquanto o comportamento adaptativo se refere a um grupo de habilidades conceituais, sociais e práticas, que são comumente aprendidas e utilizadas pelos indivíduos no seu dia-dia. 
número de pesquisas publicadas envolvendo o ensino de Ciências para estudantes com deficiência intelectual no ensino regular das redes estaduais.

\section{Metodologia}

Para realizar este trabalho utilizamos como metodologia a revisão bibliográfica do tipo narrativa, onde tivemos como base apenas alguns trabalhos ou fontes sobre o assunto tendo em vista a necessidade de se identificar os estudos já realizados sobre o assunto para delimitarmos o diferencial da nossa pesquisa. De acordo com Vianna (2001), para proporcionar o avanço em um campo do conhecimento é preciso primeiro conhecer o que já foi realizado por outros pesquisadores e quais são as fronteiras do conhecimento naquele momento histórico.

Para Lakatos e Marconi (2010), trata-se de uma metodologia indispensável para a delimitação do problema em um projeto de pesquisa, tanto para obter uma ideia precisa sobre o estado atual dos conhecimentos sobre um tema, como também suas lacunas e ainda sobre a contribuição da investigação para o desenvolvimento do conhecimento. Além disso, auxilia na definição dos objetivos da pesquisa científica. Conforme Medeiros e Tomasi (2008), a revisão bibliográfica também contribui nas construções teóricas, nas comparações e na validação de resultados de trabalhos de conclusão de curso e de artigos científicos.

Nesta pesquisa, identificamos 30 estudos, que distribuímos em: Artigos, Dissertações, Teses e Trabalhos de Conclusão de Curso, publicados entre os anos de 2015 a 2019. Realizamos a busca no período de outubro de 2018 a maio de 2019 em diversas páginas, sites e revistas, tais como: bases de dados da Scientific Electronic Library Online (SciELO); Coordenação de Aperfeiçoamento de Pessoal de Nível Superior (CAPES), revistas $e$-Curriculum; Currículo sem fronteiras; Espaço do currículo; Educação Especial; Educação Inclusiva; Movimento; Pedagogia em foco; Revista de Educação, Linguagem e Literatura (REVELLI), dentre outras. Para isso, utilizamos os seguintes descritores nos resumos, títulos e palavras chave: Currículo/ Curriculares; Inclusão/ Educação Inclusiva; Formação de Professores; Adaptação/Flexibilização/ Adequação; Deficiência Intelectual e Ensino de Ciências.

Após a identificação dos trabalhos, analisamos as trinta publicações (Quadro 1) e, para este estudo, selecionamos aquelas que traziam informações relevantes sobre o processo de inclusão escolar de alunos com deficiência intelectual (DI), bem como a relação entre a flexibilização ou adaptação curricular e o ensino de Ciências.

Quadro 1 - Publicações selecionadas em ordem crescente de data de publicação

\begin{tabular}{|c|c|c|c|c|}
\hline Título & Autor & Palavras-chave & Local da publicação & Ano \\
\hline $\begin{array}{llll}\text { 1.Alunos } & \text { com } & \text { deficiência } \\
\text { intelectual } & \text { e } & o & \text { ensino de } \\
\text { ciências. } & & & \end{array}$ & GADI, M. C. & $\begin{array}{c}\text { Aprendizagem. Deficiência } \\
\text { intelectual. Educação ambiental. } \\
\text { Atividades lúdicas. Inclusão escolar. }\end{array}$ & $\begin{array}{l}\text { Plataforma Sucupira- } \\
\text { Universidade Federal de } \\
\text { Alagoas- UFAL- } \\
\text { Dissertação. }\end{array}$ & 2015 \\
\hline $\begin{array}{ll}\text { 2.Currículo escolar e inclusão } \\
\text { de estudantes com } \\
\text { deficiência: diálogos com } \\
\text { uma escola pública. }\end{array}$ & SOARES, M T. N. & $\begin{array}{l}\text { Currículo escolar. Estudantes com } \\
\text { deficiência. Diálogo. Pesquisa-ação- } \\
\text { colaborativa. }\end{array}$ & $\begin{array}{c}\text { Universidade do Rio } \\
\text { Grande do Norte- UERN- } \\
\text { Tese. }\end{array}$ & 2015 \\
\hline $\begin{array}{l}\text { 3.Adaptação curricular para } \\
\text { alunos com deficiência } \\
\text { intelectual no relato de } \\
\text { professores das escolas } \\
\text { estaduais paulistas. }\end{array}$ & $\begin{array}{l}\text { GUADAGNINI, L e } \\
\text { DUARTE, } M .\end{array}$ & $\begin{array}{c}\text { Educação Especial. Currículo. } \\
\text { Deficiência intelectual. Inclusão } \\
\text { escolar. }\end{array}$ & $\begin{array}{l}\text { Revista Espaço Do } \\
\text { Currículo, v.8, n.3, p. } 437 \text { - } \\
\text { 452, setembro a dezembro } \\
\text { de } 2015 \text {. Artigo. }\end{array}$ & 2015 \\
\hline $\begin{array}{l}\text { 4.Currículo e Educação } \\
\text { Especial: uma relação de (re) } \\
\text { invenção necessária a partir } \\
\text { das imagens-narrativas dos } \\
\text { cotidianos escolares. }\end{array}$ & $\begin{array}{l}\text { HAAS, C. BAPTISTA, } \\
\text { C. R. }\end{array}$ & $\begin{array}{l}\text { Currículo; Educação Especial; } \\
\text { Acessibilidade Curricular; } \\
\text { Atendimento Educacional } \\
\text { Especializado. }\end{array}$ & $\begin{array}{c}\text { ANPEd - 04 a 08 de } \\
\text { outubro de 2015, UFSC - } \\
\text { Florianópolis-2015. Artigo. }\end{array}$ & 2015 \\
\hline
\end{tabular}


Research, Society and Development, v. 10, n. 17, e166101723997, 2021

(CC BY 4.0) | ISSN 2525-3409 | DOI: http://dx.doi.org/10.33448/rsd-v10i17.23997

\begin{tabular}{|c|c|c|c|c|}
\hline $\begin{array}{l}\text { 5.Atividades lúdicas } \\
\text { ensino de ciências para } \\
\text { alunos da educação especial. }\end{array}$ & MELO, B.M. & Aprendizagem - Lúdico - Ciências. & UNILA-PR Dissertação. & 2015 \\
\hline $\begin{array}{l}\text { 6.Adequação curricular para } \\
\text { uma prática educacional } \\
\text { inclusiva. }\end{array}$ & SILVA, M. R. & $\begin{array}{c}\text { Escola Inclusiva. Formação } \\
\text { Continuada. Adequações Curriculares. }\end{array}$ & $\begin{array}{l}\text { Universidade de Brasília- } \\
\text { DF. TCC. }\end{array}$ & 2015 \\
\hline $\begin{array}{l}\text { 7.A Inclusão Escolar no } \\
\text { ensino de ciências - uma } \\
\text { discussão das concepções dos } \\
\text { professores na formação } \\
\text { continuada. }\end{array}$ & $\begin{array}{l}\text { SANTOS, L. A. J.; } \\
\text { DUARTE, A. C. S. }\end{array}$ & $\begin{array}{l}\text { Inclusão. Ensino de Ciências. } \\
\text { Formação continuada. }\end{array}$ & $\begin{array}{l}\text { Revista Educon, Aracaju, } \\
\text { Volume 10, n. 01, p.1-14, } \\
\text { 2016. Artigo. }\end{array}$ & 2016 \\
\hline $\begin{array}{l}\text { 8.As Práticas e as Políticas } \\
\text { curriculares de inclusão e o } \\
\text { direito à diferença. }\end{array}$ & $\begin{array}{l}\text { SEPULVEDA, J. A.; } \\
\text { SEPULVEDA, D. }\end{array}$ & $\begin{array}{l}\text { Currículo. Políticas Públicas. Práticas } \\
\text { Emancipatórias. }\end{array}$ & $\begin{array}{c}\text { Revista } e \text {-Curriculum, São } \\
\text { Paulo, v. } 14, \text { n.04, p. } 1258- \\
1287 \text { out./dez.2016. } \\
\text { Artigo. }\end{array}$ & 2016 \\
\hline \begin{tabular}{lr} 
9.Flexibilização & \multicolumn{2}{c}{ Curricular: } \\
um caminho para o \\
atendimento dos alunos com \\
deficiência intelectual no \\
contexto da educação de \\
jovens e adultos.
\end{tabular} & $\begin{array}{l}\text { ELIAS, E. R.; BRIDI, J. } \\
\text { C.A. }\end{array}$ & $\begin{array}{c}\text { Educação de Jovens e Adultos. } \\
\text { Inclusão. Deficiência. Flexibilização } \\
\text { Curricular. }\end{array}$ & Cadernos PDE-PR. & 2016 \\
\hline $\begin{array}{l}\text { 10.Adaptações Curriculares e } \\
\text { a Inclusão Educacional da } \\
\text { Pessoa em Situação de } \\
\text { Deficiência: um estudo de } \\
\text { caso em escolas públicas } \\
\text { localizadas no município de } \\
\text { Belém/PA. }\end{array}$ & PAULA, H. I. G. & $\begin{array}{c}\text { Inclusão Educacional. Adaptações } \\
\text { Curriculares. Pessoa em situação de } \\
\text { deficiência. }\end{array}$ & $\begin{array}{l}\text { Universidade Federal do } \\
\text { Pará- UFPA-Dissertação. }\end{array}$ & 2016 \\
\hline $\begin{array}{l}\text { 11.Panorama inclusivo na } \\
\text { perspectiva do ensino de } \\
\text { ciências em escolas de nível } \\
\text { fundamental da cidade de } \\
\text { Codó - Maranhão. }\end{array}$ & $\begin{array}{l}\text { MARQUES, C. V. V. } \\
\text { C. O.; COELHO, E. T. } \\
\text { A. }\end{array}$ & $\begin{array}{l}\text { Percepções dos professores; Inclusão } \\
\text { Social; Ensino de Ciências. }\end{array}$ & $\begin{array}{c}\text { Revista Educação, Arte e } \\
\text { Inclusão vol.12, n.3.2016. } \\
\text { Artigo. }\end{array}$ & 2016 \\
\hline $\begin{array}{l}12.0 \text { currículo na escola } \\
\text { inclusiva: uma perspectiva na } \\
\text { educação especial. }\end{array}$ & $\begin{array}{c}\text { REGO, J. K.; } \\
\text { BARRETO, R Q.; } \\
\text { BENÍCIO, D R F. }\end{array}$ & Currículo. Inclusão. Escola. & $\begin{array}{l}\text { II CINTEDI-Congresso } \\
\text { internacional de educação } \\
\text { inclusiva- Campina } \\
\text { Grande-PB. Artigo. }\end{array}$ & 2016 \\
\hline $\begin{array}{lrr}\text { 14.Currículo } & \text { e } & \begin{array}{r}\text { Deficiência } \\
\text { intelectual: } \\
\text { discursivas } \\
\text { escolar. }\end{array} \\
\text { eno } & \text { contexto } \\
\end{array}$ & SILVA, G.E.G. & $\begin{array}{l}\text { Diferença. Identidade. Teoria do } \\
\text { Discurso. }\end{array}$ & $\begin{array}{l}\text { Currículo sem Fronteiras, } \\
\text { v. 17, n. 3, p. 814-832, } \\
\text { set./dez. 2017. Artigo. }\end{array}$ & 2017 \\
\hline $\begin{array}{lr}\text { 15.Educação } & \text { Especial: } \\
\text { inclusão, } & \text { currículo } \\
\text { diversidade. } & \end{array}$ & SOUZA, A.M. & $\begin{array}{c}\text { Educação Inclusiva. Diversidade. } \\
\text { Currículo. }\end{array}$ & $\begin{array}{c}\text { Revista de Pesquisa } \\
\text { Interdisciplinar, Cajazeiras, } \\
\text { v. 2, n. 2, 207-216, jun/dez. } \\
\text { de 2017. Artigo. }\end{array}$ & 2017 \\
\hline $\begin{array}{l}\text { 16.Das Adaptações às } \\
\text { Flexibilizações Curriculares: } \\
\text { uma análise de documentos } \\
\text { legais e revistas pedagógicas. }\end{array}$ & $\begin{array}{l}\text { SCHERER, R. P.; } \\
\text { GRÄFF, P. }\end{array}$ & $\begin{array}{c}\text { Adaptações Curriculares. } \\
\text { Aprendizagem. Necessidades } \\
\text { Educacionais Especiais. Inclusão } \\
\text { escolar. }\end{array}$ & $\begin{array}{l}\text { Revista } e \text {-Curriculum, São } \\
\text { Paulo, v.15, n.2, p. } 376- \\
400 \text { abr./jun.2017. Artigo. }\end{array}$ & 2017 \\
\hline $\begin{array}{l}\text { 17. Currículo e Inclusão: } \\
\text { reflexões sobre os conteúdos } \\
\text { de escolarização para alunos } \\
\text { com deficiência. }\end{array}$ & MESQUITA, A. M. A. & $\begin{array}{l}\text { Currículo. Inclusão. Escolarização. } \\
\text { Alunos com Deficiência. }\end{array}$ & $\begin{array}{c}\text { Inclusão Social, Brasília, } \\
\text { DF, v.11 n.1, p.67-80, } \\
\text { jul./dez. 2017. Artigo. }\end{array}$ & 2017 \\
\hline $\begin{array}{l}\text { 18. O Ensino de Física para } \\
\text { Jovens com Deficiência } \\
\text { Intelectual: uma proposta } \\
\text { para facilitar a inclusão na } \\
\text { escola regular. }\end{array}$ & SANTOS, A. M, et.al. & $\begin{array}{l}\text { Educação Inclusiva. Ensino de Física. } \\
\text { Deficiência Intelectual. }\end{array}$ & $\begin{array}{l}\text { Revista Educação Especial, } \\
\text { v. 32-2017. Artigo. }\end{array}$ & 2017 \\
\hline $\begin{array}{l}\text { 19. O Ensino de Ciências nas } \\
\text { Salas de Recursos } \\
\text { Multifuncionais: } \\
\text { contribuições do enfoque } \\
\text { CTS para a prática } \\
\text { pedagógica inclusiva. }\end{array}$ & $\begin{array}{c}\text { VIER, R, F, S } \\
\text { SILVEIRA, R, M, C, F, } \\
\text { S. }\end{array}$ & $\begin{array}{l}\text { Inclusão Educacional. Sala de } \\
\text { Recursos Multifuncional (SRM). } \\
\text { Ensino de Ciências. Ciência, } \\
\text { Tecnologia e Sociedade (CTS). }\end{array}$ & $\begin{array}{c}\text { Experiências em Ensino de } \\
\text { Ciências V.12, No. } 72017 . \\
\text { Artigo. }\end{array}$ & 2017 \\
\hline
\end{tabular}




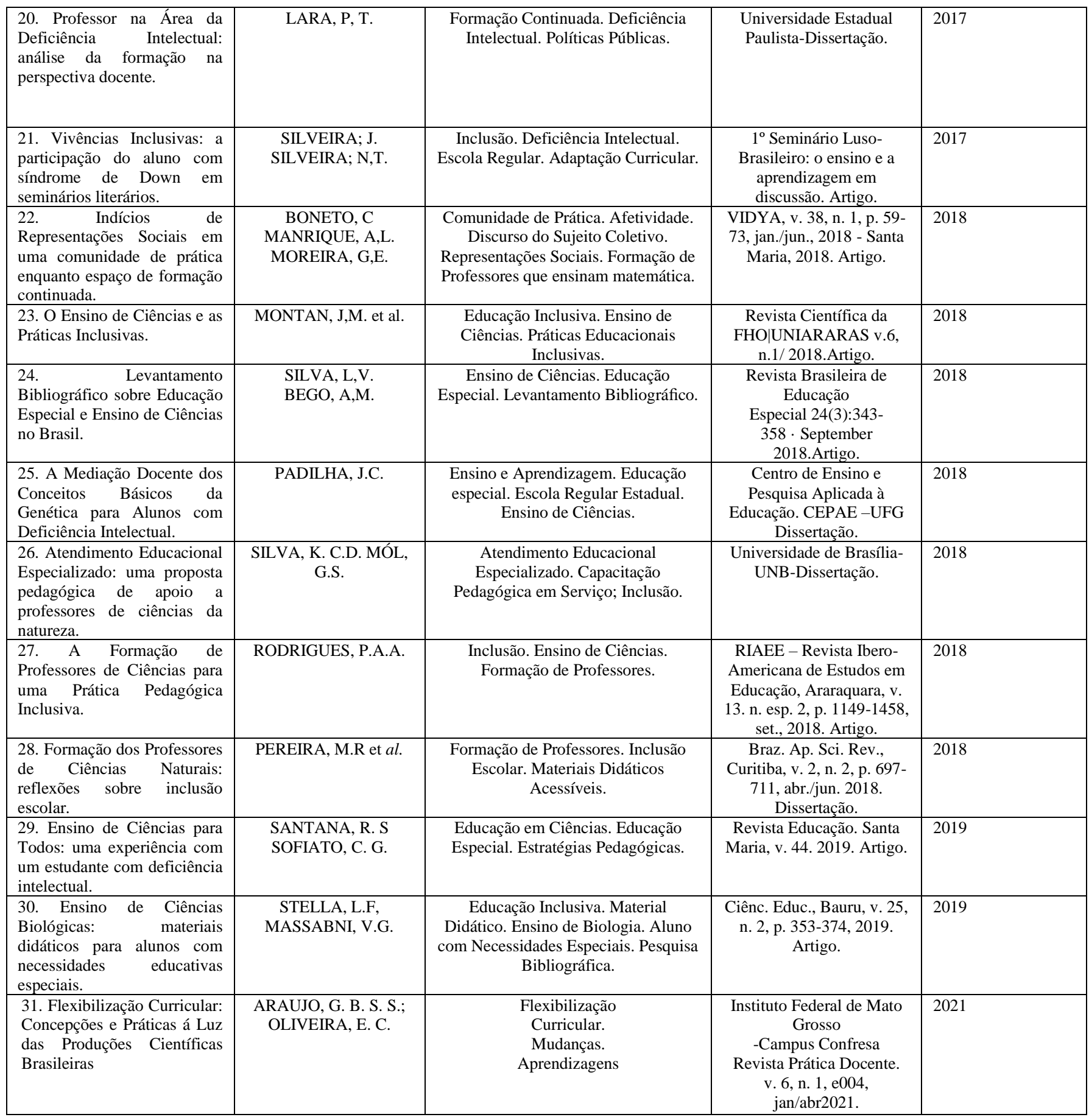

Fonte: Autores.

Os estudos selecionados e analisados nessa revisão foram desenvolvidos por profissionais da área da educação e por professores de diversas áreas do conhecimento, como: Pedagogia, Matemática, Ciências da natureza, linguagens e códigos. Em as pesquisas, buscamos por trabalhos que envolviam, direta e indiretamente, a educação inclusiva. Essa grande articulação entre profissionais de áreas distintas possibilita trocas de experiências e diferentes pontos de vistas sobre um mesmo fato. Apresentamos abaixo o Quadro 2 no qual apontamos os descritores elencados e o número de vezes em que aparecem nas publicações. 
Quadro 2 - Ocorrência dos Descritores nos Artigos Pesquisados.

\begin{tabular}{|l|l|}
\hline Descritores & Frequência \\
\hline Currículo/Curriculares & 05 \\
\hline Educação especial & 03 \\
\hline Educação Inclusiva/Inclusão & 02 \\
\hline Formação de Professores & 03 \\
\hline Adaptação/ Adequação/ Flexibilização & 04 \\
\hline Deficiência Intelectual & 08 \\
\hline Ensino de Ciências & 06 \\
\hline
\end{tabular}

Fonte: Autores.

\section{Resultados e Discussão}

Considerando o objetivo deste estudo, os dados analisados evidenciam a ocorrência de da utilização dos descritores: adaptações, adequações e de flexibilizações curriculares como sinônimos em Silva (2015); Guardani e Duarte (2015); Silva (2018); Paula et al. (2016), corroborando com o processo de integração conforme Mantoan (2003), no entanto, contradizem os princípios da educação inclusiva porque prevê serviços educacionais segregados e acesso restrito ao currículo oficial.

Por outro lado, percebemos um avanço nas concepções de adaptação e flexibilização curricular em Scherer e Graff (2017), que esclarecem como o currículo foi sendo moldado para atender às metas estabelecidas para a educação durante os últimos anos do século XX. As autoras concluem que as adaptações curriculares e, mais recentemente, as flexibilizações curriculares visam atender às demandas de uma educação que acompanha as transformações sociais.

Souza (2017) investigou alguns aspectos da trajetória histórica da educação inclusiva, bem como os modelos de pensamento que a abarcaram e as mudanças de paradigma que perpassam a mesma, observando o processo de inclusão que foi se estabelecendo na escola. Para tanto, a autora considerou o currículo e suas adaptações durante o seu percurso. Neste contexto, Mesquita (2017) destaca que o não engessamento dos currículos vai ao encontro das práticas curriculares inclusivas que seriam aquelas que possibilitam ao aluno em situação de deficiência participar, produzir e se apropriar da cultura própria da escola. Corroborando com esse estudo, Santos et al. (2017), concluem que esse debate é necessário tendo em vista que o direito à educação não se resume a estar inserido em uma escola, mas em poder se constituir como sujeitos e produtores de conhecimento.

Por esse motivo, Rego et al. (2016) questionam em que medida o currículo está contribuindo para o processo de inclusão e sugerem que, para superar a lógica das adaptações, é preciso uma proposta curricular construída na perspectiva de viabilizar a articulação dos conhecimentos no ensino regular, entendendo que a educação inclusiva deve promover a ampliação dos conhecimentos, das experiências de vida e a valorização dos percursos de aprendizagem.

Ainda sobre os desafios relacionados à inclusão escolar, Hass e Baptista (2015) apontam a precariedade do debate acadêmico acerca desse assunto e ressaltam a importância do investimento na compreensão do conceito acessibilidade curricular. Em consonância com este estudo, Santos e Duarte (2016) esclarecem que os professores revelam um discurso coerente com os princípios e bases da educação inclusiva, porém, questionável quando comparado com as revelações e dilemas da prática, uma vez que esta exige espaços de reflexão e formação continuada; o que também foi constatado por Marques e Coelho (2016), que apontaram a necessidade de uma formação continuada para o contexto inclusivo.

Mesquita (2017) acrescenta que a inclusão de estudantes com deficiência na escola regular tem sido marcada no atual contexto por um debate intenso sobre o processo de escolarização do público alvo da educação especial que desemboca no currículo que é destinado/produzido para esses estudantes, tanto na sala regular quanto na Sala de Recursos Multifuncionais (SRM). A autora destaca que as práticas curriculares para a inclusão de estudantes com deficiência devem ter intencionalidade 
pedagógica definida, caso contrário, podem operar apenas como mera ocupação do tempo desses estudantes na escola, fragilizando sua escolarização.

Boneto et al. (2018) apontaram para a importância de um ambiente culturalmente diverso onde haja o fazer conjunto e a ressignificação do habitus e ainda a constituição de um ambiente potencialmente positivo no qual a aprendizagem, individual e coletiva, se torne o principal objetivo a ser alcançado. Os autores consideraram as comunidades de prática como um importante espaço de formação continuada que permite, além da formação, a transformação pessoal e coletiva dos professores que dela participam.

Quanto à formação continuada, Silva (2018); Lara (2017); Padilha (2018); Rodrigues (2018) e Pereira (2018) defendem que a reflexão e trocas de experiências no ambiente de serviço, coopera com a promoção da inclusão uma vez que proporciona ao docente a possibilidade de (re) construção de suas práticas. Ao mesmo tempo, essas ações práticas contribuem com a aprendizagem de estudantes com deficiência intelectual no desenvolvimento do pensamento crítico sobre as relações existentes entre ciência, tecnologia e as consequências para a sociedade e ambiente, como foi constatado por Vier e Silveira (2017) quando utilizaram o enfoque Ciência - Tecnologia - Sociedade (CTS) ou Ciência-Tecnologia-Sociedade-Ambiente (CTSA) no ensino de Ciências nas Salas de Recursos Multifuncionais.

Sobre a diversidade e diferença, Sepulveda e Sepulveda (2016) apresentam um estudo que precisa ser levado em consideração na atualidade: a questão de gênero. Segundo os autores, em uma sociedade conservadora como a brasileira, tais discussões são extremamente pertinentes. O enfoque da pesquisa está na luta por políticas de currículo que defendam o direito às diferenças e que estas não podem ser reduzidas a políticas de inclusão que não privilegiam todas as diferenças.

A busca de múltiplas estratégias de aprendizagem que posicionem o estudante no centro do seu processo de aprendizagem são as novas tendências no ensino de Ciências. Essa tendência corrobora com Melo (2015), que comprova por meio de sua pesquisa a contribuição das atividades lúdicas no ensino de Ciências para estudantes da educação inclusiva. Assim como Gadi (2015), que mostra como a proposta de transposição dos conhecimentos do cotidiano dos catadores de mariscos para a linguagem científica ocorreu com o auxílio da ludicidade. Como resultado, a autora constatou tanto a apropriação dos conhecimentos científicos como a socialização dos alunos com e sem deficiência no ambiente escolar.

Santana e Sofiato (2019); Stella e Massabni (2019) evidenciaram a eficácia do uso de diferentes estratégias para ensinar Ciências a estudantes com deficiência intelectual, como a utilização de recursos didáticos lúdicos, multissensoriais, envolvendo diferentes linguagens e atividades investigativas. Todavia, os estudos realizados por esses autores mostraram alguns desafios, a saber: o pouco tempo remunerado disponível para o planejamento das atividades pedagógicas e a grande quantidade de alunos em sala de aula bem como a necessidade de mais estudos relacionados à criação de recursos didáticos que possam ser utilizados em sala de aula na área de Biologia por alunos com deficiência.

Ademais, na tese defendida por Araújo e Oliveira (2021), ficou evidente que "A flexibilização curricular deve ser construída por meio de conteúdos flexíveis, bem como por métodos ativos e práticas pedagógicas inovadoras e pelo desenvolvimento de atividades complementares. Dessa forma, tais relações podem promover aprendizagens autônomas, críticas, reflexivas e transformadoras nos alunos".

\section{Conclusão}

Ao iniciar este estudo, definimos como objetivo - identificar elementos de exclusividade como a flexibilização curricular no ensino de Ciências para estudantes com alguma deficiência, especificamente deficiência intelectual, nas publicações científicas brasileiras dos últimos cinco anos. E, após fazer uma busca por 30 estudos, distribuídos em Artigos, Dissertações, Teses e Trabalhos de Conclusão de Curso, publicados entre os anos de 2015 a 2019, vimos que houve avanços no 
que se refere à educação inclusiva.

Percebemos a necessidade da formação continuada do professor para que possa promover trocas de experiências para a inserção de elementos de inclusividade, bem como a flexibilização curricular que se configura nas múltiplas estratégias e materiais que possam atender as singularidades dos sujeitos. Consideramos, ainda, a necessidade dos conhecimentos prévios dos estudantes transformando-os em conhecimentos científicos, a fim de promover a intervenção ética e responsável do estudante na sua realidade e a reflexão coletiva sobre currículo e conhecimento escolar no contexto inclusivo.

As publicações apresentaram um rico acervo de experiências e estratégias pedagógicas que podem favorecer a aprendizagem dos estudantes com e sem deficiência e dar subsídios aos professores, a exemplo de: atividades lúdicas; teatro; tecnologias assistivas; utilização da semiótica, oportunizando a linguagem verbal e não verbal e os recursos imagéticos que são estruturas abstratas e genéricas advindas da dinâmica da imagem caracterizada pela observação humana; dentre outros. Vimos, ainda, a abordagem CTSA que permite o desenvolvimento do pensamento crítico sobre as relações existentes entre Ciência, tecnologia e as consequências para a sociedade e ambiente.

Nesse contexto, é grande a possibilidade de efetivação da educação inclusiva. Entretanto, sabemos que ainda há um longo percurso pela frente para que a inclusão escolar seja efetivada. E, diante do que apresentamos neste artigo/capítulo, é possível encontrar diversos exemplos de estratégias e práticas pedagógicas exitosas que nos trazem evidências concretas de um dos princípios fundamentais da educação inclusiva: Todos aprendem!

\section{Referências}

Araújo, G. B. S. S.; \& Oliveira, E. C. (2021). Flexibilização Curricular: Concepções E Práticas À Luz Das Produções Científicas Brasileiras. Revista Prática Docente, 6(1), e 004 .

Bachelard, G. (2005). A formação do espírito científico. (5a ed.), Ed. Contraponto.

Boneto, C.; Manrique, A, L.; \& Moreira, G, E. (2018). Indícios de Representações Sociais em uma comunidade de prática enquanto espaço de formação continuada. Santa Maria. VIDYA, 38(1), 59-73.

Boneto, C; Manrique, A. L; \& Moreira, G. E. (2018). Indícios de representações sociais em uma comunidade de prática enquanto espaço de formação continuada. VIDYA, 38, 59-73.

Brasil, Estatuto da Criança e do Adolescentel Secretaria Especial dos Direitos Humanos; Ministério da Educação, Assessoria de Comunicação Social. Brasília: MEC, ACS, 2005.

Brasil, Constituição da República Federativa do Brasil. Brasília, 1988.

Brasil, Declaração Mundial sobre Educação para todos: plano de ação para satisfazer as necessidades básicas de aprendizagem. (1990). UNESCO, Jomtiem/Tailândia.

Brasil, Lei Federal №. 9394 de 20 de dezembro. Diretrizes e Bases da Educação Nacional. Diário Oficial da República Federativa do Brasil. Brasília, 1996. http://www.in.gov.br/mp._leis/leis_texto.asp.

Brasil, Ministério da Educação. (2008). Secretaria de Educação Especial. Política Nacional de Educação Especial na perspectiva da Educação Inclusiva. Brasília: MEC/SEESP,

Brasil, Política de educação inclusiva (2007). www.mec.gov.br.

Elias, E. R; \& Bridi, J. C. A. (2016). Flexibilização curricular: um caminho para o atendimento dos alunos com deficiência intelectual no contexto da educação de jovens e adultos. Cadernos PDE.

Gadi, M. C. (2015). Alunos com deficiência intelectual e o ensino de ciências. Dissertação (ensino de ciências e matemática) Universidade Federal De Alagoas. Maceió.

Guadagnini, L.; \& Duarte, M. (2016). Adaptação curricular para alunos com deficiência intelectual no relato de professores das escolas estaduais paulistas. Revista espaço do currículo. 08(3). UFPB.

Haas, C.; \& Baptista, C. R. (2015). Currículo e educação especial: uma relação de (re) invenção necessária a partir das imagens-narrativas dos cotidianos escolares. Anped - Associação Nacional de Pós-Graduação e Pesquisa em Educação.

Lakatos, E. M; \& Marconi, M. A. (2010). Fundamentos de Metodologia Científica. ATLAS EDITORA. 
Lara, P, T. (2017). Professor na Área da Deficiência Intelectual: análise da formação na perspectiva docente. (Dissertação) Universidade Estadual Paulista.

Lopes, A. C; \& Macedo, E. (2011). Teorias de Currículo. Cortez.

Marques, C. V. Vieira, C. O. Coelho, E. T.A. (2016). O Panorama inclusivo na perspectiva do ensino de ciências em escolas de nível fundamental da cidade de Codó - Maranhão. Revista Educação, Artes e Inclusão. Universidade do Estado de Santa Catarina - UDESC 12(3).

Medeiros, J. B. \& Tomasi, C. (2008). Comunicação Científica. Atlas.

Melo, B. M. (2015). Atividades lúdicas no ensino de ciências para alunos da educação especial. Dissertação de mestrado (ciências da vida e da natureza licenciatura em ciências da natureza - biologia, física e química). Foz Do Iguaçu - PR. Universidade. Federal Da Integração Latino Americana - UNILA.

Mesquita, A. M. A. (2017). Currículo e inclusão: reflexões sobre os conteúdos de escolarização para alunos com deficiência. Revista Inclusão Social. Brasília, DF, 11(1), 67-80.

Migliori. A. (2017). Educação especial: inclusão, currículo e diversidade. Campina Grande- PB. Revista de Pesquisa Interdisciplinar, Revista de pesquisa interdisciplinar. 2(2).

Miranda, A. D; \& Pinheiro, N. A. M. (2018). O ensino da Matemática ao deficiente intelectual: projetos de trabalho em uma perspectiva contextualizada e interdisciplinar. Revista Educação Especial, 29(56), 695-708, 2016. Disponível em: https://periodicos.ufsm.br/educacaoespecial/article/view/17805/pdf.

Montan, J. M. et al. (2018). O ensino de ciências e as práticas inclusivas. Revista Científica da FHO|UNIARARAS 6(1).

Oliveira, M. K. (1997). Vygotsky: aprendizado e desenvolvimento um processo sócio-histórico. Scipione,

Padilha, J. C. (2018). A mediação docente dos conceitos básicos da genética para alunos com deficiência intelectual. Dissertação de Mestrado. Centro Ensino Pesquisa Aplicada Educação-UFG. Goiás.

Paula, H. I. G. (2016). Adaptações curriculares e a inclusão educacional da pessoa em situação de deficiência: um estudo de caso em escolas públicas localizadas no município de Belém/PA. Belém/PA. Dissertação. UNIVERSIDADE FEDERAL DO PARÁ. UFPA.

Pereira, M. R et al. (2018). Formação dos Professores de Ciências Naturais: reflexões sobre inclusão escolar. Braz. Ap. Sci. Rev., 2(2), 697-711.

Rego, J. K. Barreto, R. Q. \& Benício, D. R. F. (2016). O currículo na escola inclusiva: uma perspectiva na educação especial. II CINTED.

Rodrigues, P.A.A. (2018). A Formação de Professores de Ciências para uma Prática Pedagógica Inclusiva. RIAEE - Revista Ibero-Americana de Estudos em Educação, Araraquara, 13, 1149-1458

Santana, R. S.; \& Sofiato, C. G. (2019). Ensino de Ciências para Todos: uma experiência com um estudante com deficiência intelectual. Santa Maria-SC. Revista Educação., 44.

Santos, A. M, et.al. (2017). O Ensino de Física para Jovens com Deficiência Intelectual: uma proposta para facilitar a inclusão na escola regular. Revista Educação Especial, 32-

Santos, Â. M., Carvalho, P. S. \& Alecrim, J. L. (2019). O ensino de física para jovens com deficiência intelectual: uma proposta para facilitar a inclusão na escola regular. Revista Educação Especial, 32.

Santos, L. A. J. \& Duarte A. C. S. (2016). A inclusão escolar no ensino de ciências - uma discussão das concepções dos professores na formação continuada. Aracajú SE. Educon. 10(1),.1-14.

Santos, S; \& Morato, P. (2012). Acertando o passo! Falar de deficiência mental é um erro: deve se falar de deficiência intelectual e desenvolvimental (DID). Por quê? Rev. Bras. Educ. Espec. 18(1), 3-16,

Scherer, R. P; \& Gräff, P. (2017). Das adaptações às flexibilizações curriculares: uma análise de documentos legais e revistas pedagógicas. Revista eCurriculum, 15(2), $376-400$

Sepulveda, J. A. \& Sepulveda, Denize. (2016). As práticas e as políticas curriculares de inclusão e o direito à diferença. Revista e-Curriculum, São Paulo, $14(4), 1258-1287$

Silva, M. R. (2018). Adequação curricular para uma prática educacional inclusiva. Universidade de Brasília (Instituto de Psicologia). TCC.

Silva, S. C. R; Shimazaki, E. M; \& Menegassi, R. J. (2017). A formação de conceitos em ciências naturais por alunos com deficiência intelectual. Enseñanza de las Ciencias, n. Extra, 1203-1207, https://ddd.uab.cat/pub/edlc/edlc_a2017nEXTRA/26.

Silva, K. C. D. \& Mól, (2018). G. S. Atendimento educacional especializado: uma proposta pedagógica de apoio a professores de Ciências da Natureza. Brasília-DF. Dissertação. Universidade de Brasília- UNB.

Soares, M. T. N. (2015). Currículo escolar e inclusão de estudantes com deficiência: diálogos com uma escola pública. Dissertação (centro de ciências aplicadas).

Souza, A.M. (2017). Educação Especial: inclusão, currículo e diversidade. Cajazeiras- PB. Revista de Pesquisa Interdisciplinar, 2(2), $207-216$.

Stella, L.F; \& Massabni, G. (2019). Ensino de Ciências Biológicas: materiais didáticos para alunos com necessidades educativas especiais. Ciênc. Educ., Bauru, 25(2), 353-374.

Tavares, A. R. (2013). Curso de Direito Constitucional. São Paulo-SP. Saraiva.

Vianna, I. O. (2001). Metodologia do trabalho científico: um enfoque didático da produção científica. EPU,

Vier. R. F. S. \& Silveira. R. M. C. F. (2017). O ensino de ciências nas salas de recursos multifuncionais: contribuições do enfoque CTS para a prática pedagógica inclusiva. Revista Experiências em Ensino de Ciências. 12(7) 